\title{
ANALISIS INTERACTIVO DE TEXTOS ORALES: LA ENTREVISTA
}

\author{
ELISA C. ZAMORA PÉREZ \\ (Universidad de Murcia)
}

\section{Introducción}

La necesidad de estudios interdisciplinares ha sido postulada en las últimas décadas, desde el seno de diferentes disciplinas, pues dada la profundidad y especialización de las ciencias es necesaria la confrontación con otros campos y metodologías, y sobre todo, la colaboración en la aportación de los distintos datos provenientes de cada una de ellas, con el fin de llegar a un diálogo intelectual que ayude a superar los límites con que cada rama ha de enfrentarse. Como otros objetos de estudio, el análisis del discurso no puede ser abordado por una sola ciencia ya que en él confluyen todos aquellos focos de interés relacionados con el hombre y su capacidad de comunicarse.

Hemos realizado este trabajo desde la convicción de que el análisis interacitvo es una fuente de datos por los que se puede caracterizar el comportamiento lingüístico de un hablante, posibilitando el conocimiento socio-ideológico y evidenciando que este acercamiento al discurso es un apoyo para el estudio sociológico.

Las entrevistas elegidas pertenecen a un trabajo realizado por $\mathrm{M}^{\mathrm{a}}$ Angeles Cascales y Juan Luis Chillón, titulado: Juventud en la región de Murcia 1985, los jóvenes son representantes de distintos campos, conformando un mosaico variado: concejal de juventud, persona vinculada al mundo de la droga, representante de las Juventudes Socialistas, representante de las Nuevas Generaciones, representante de un grupo rock, representante universitario, etc.

Habría que destacar que aunque los jóvenes entrevistados son murcianos las características de esta muestra pueden ser atribuidas a la juventud española de la década de los 80 , pues presentan más rasgos comunes que diferencias con respecto al panorama nacional, al ser partícipes como toda su generación de las mismas inquietudes, vivencias, con similares experiencias en sus relaciones familiares y en la incorporación al mundo laboral.

\section{Acercamiento al análisis interactivo de la conversación}

Para que el signo lingüístico nazca demanda la copresencia de al menos dos individuos. Tal como señala Guespin (1984:6), Voloshinov considera el signo como 
"résultant d'un consensus entre des individus socialment organisés au cours d'un processus d'interaction". La interacción es un proceso recíproco que consiste tanto en la transmisión de un flujo verbal, como en una serie de componentes somáticos organizados en la acción producida entre los dos participantes, en el que ambos intentan salvaguardar su postura: opinar, defenderse, replicar, etc.; todas ellas son actitudes pragmáticas que traducen la intencionalidad del hablante, manifestando aquello que ha indicado E. Ramón Trives (1980:28): "el lenguaje verificable y deontológico es un lenguaje pragmáticamente no exento".

En el estudio de la interacción hallamos dos conceptos fundamentales: comportamiento y comunicación, que responden a dos formas de interpretar la interacción: (1) enfoque pragmático, (2) enfoque semiótico. El primero tiene en cuenta el efecto producido por el emisor sobre el receptor y el que a su vez éste provoca sobre aquél, pero considerando el problema desde el punto de vista del comportamiento (gestos, posturas...), mientras que el enfoque semiótico se refiere a todo lo que ocurre antes de actuar, a ese hacer del sujeto, estudiando aquello que tiene que ver con la competencia cognoscitiva. Mas no sólo hay comunicación cuando ésta es intencional, sino que en el proceso interactivo, como señala G. Latella (1986), el otro (sujeto cognoscitivo que se halla al extremo contrario de la emision) ha de ser tomado en cuenta de forma rotunda. Esta posición enlaza con la de Psathas, expresada en un artículo titulado: "Analyzing Dyadic Interaction", en el cual postula que la díada conversacional se establece con la actitud de vigilancia mutua entre los participantes, realizándose siempre que se da un intercambio mutuo, y terminando cuando el foco de acción de cada participanmte centra su atención en algún objetivo fuera de la comunicación verbal inmediata.

La forma más compleja de interacción es la conversación, intercambio de ideas y conductas verbales y no verbales entre interlocutores. La conversación entendida como proceso es definida por D. Allen y R. F. Guy (1978:30) del siguiente modo:

"Conversation is a continuing and social process wich fundamentally involves verbal exchanges between two persons, although more than two persons may participate".

El concepto de cooperación conversacional ha sido postulado por diferentes autores, entre quienes destaca H. P. Grice con obras como "Logic and Conversation", y su incorporación al estudio de la relación interactiva emisor/receptor es muy interesante, ya que el emisor intenta producir un enunciado lo más pertinente posible, aunque esto no es sólo privilegio del emisor, sino que como A. Duranti (1986: 241) destaca, emisor y receptor son copartícipes en la proyección e interpretación de un enunciado, por lo que declara:

"Interpretation is not conceived as the speaker's privilege, on the contrary, it is based on the ability (and power) that others may have invoke certain conventions to stablish links between different acts and different personae. Mcaning is collectivelly defined on the basis of recognized (and sometimes restated) social relationships".

Así, comprensión y respuesta son mutuamente necesarias en la medida en que los roles de emisor y receptor se intercambian en la conversación y cada acto de lenguaje es ratificado por el oyente. El estudio interactivo pone de manifiesto la importancia de los planteamientos que se interesan por el lenguaje oral, manifestación nada desdeñable sobre todo si se tiene en cuenta que es la expresión de la comunicación humana, que nos convierte en sujetos sociales, siendo la conversación la célula básica que instaura la sociedad.

La interacción la entendemos como un fenómeno con doble aspecto al que se llega 
a través del estudio de problemas tanto relacionados con la conversación como con el discurso, puesto que la interacción en la conversación se asienta sobre sistemas lingüísticos y su objeto de estudio reside en la lengua. La interacción discursiva, reclama a su vez el estudio de las aportaciones psico-sociales, por lo que son necesarios dos tiempos de estudio: un tiempo estructural y otro discursivo para empezar a entender el desarrollo de la entrevista tal cual es.

Nuestro trabajo se ocupa de la entrevista, fenómeno textual que puede ser enmarcado en unos patrones específicos que organizan un texto peculiar, situado dentro del arte de conversar, cuyo principio general es la coordinación de los participantes, en la instauración de un turno de preguntas y respuestas, presididas por un cuestionario, eje central, que se constituye en guía a la que ambos hablantes han de acogerse, limitando sus participaciones.

\section{Análisis interactivo de la entrevista}

\subsection{Aportación metodológica}

Para la elaboración de nuestra metodología nos hemos servido de una pluralidad de fuentes que nos han ayudado a perfilar el concepto de interacción, en las que destacan autores como D. Allen, R. F. Guy, Watzlawick, R. Birdwhistell, E. Roulet, L. Guespin, G. Latella, etc. En cuanto a la elaboración de nuestro método de análisis, la aportación de L. Guespin nos ha sido de gran utilidad, ya que él propone dos formas para la representación descriptiva y estructurada de la conversación: el sistema arbóreo y el sistema de cajas, que es el que hemos elegido en nuestro trabajo:

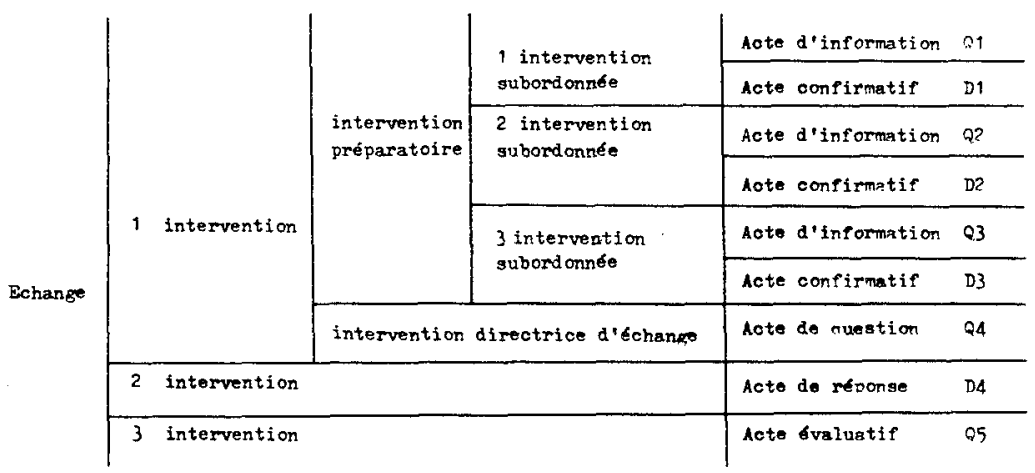

Siguiendo la terminología de este autor hemos dividido las entrevistas en intercambios, intervenciones y actos de lenguaje '.

Consideramos intercambio un fragmento de discurso que se establece (teniendo en

'Para la claboración de esta metodología hemos definido según nuestro criterio tanto los conceplos de intercambio e intervención, como ciertos actos de lenguaje que ponen de manifiesto el fenómeno textual que tratamos tales como: acto de refrendo, acto de ayuda, acto de presentación, acto de aserción ejemplificaliva, cic. 
cuenta el tipo de texto que es la entrevista y la especial relación de poder que en ella se desarrolla) siempre y cuando el entrevistador considere satisfactorios los términos en los que se ha dado la respuesta a su pregunta, pudiendo cambiar de tema cuando crea cubiertas dichas expectativas. La extensión y los criterios son variables. Entre los criterios que marcan la pauta para que se realice un cambio de intercambio están: la presentación de un tema nuevo por parte del entrevistador, o razones fortuitas como pueden ser la pérdida del desarrollo de la conversación, con el consecuente olvido del tema, debido a la falta de atención, nerviosismo u otros factores. Siempre que el entrevistador no crea cubierta la información puede reincidir sobre el tema, concretando más la pregunta, perfilándola. El intercambio puede alargarse cuando el locutor entrevistado introduce un elemento remático interesante para el tema, pudiendo el entrevistador volver sobre ese asunto con más preguntas. El intercambio estará compuesto por dos o más intervenciones, siempre dentro de la dinámica pregunta-respuesta, aunque esta relación puede modificarse.

La intervención quedará constituida cada vez que un interlocutor tome la palabra, siempre que esté dentro de la relación diádica de la entrevista, su intervención tiene que estar relacionada con el desarrollo de los contenidos acerca de los que se está hablando.

Los actos de lenguaje suponen la dimensión social e interpersonal del comportamiento lingüístico. Cada intervención puede estar formada por uno o varios, expresando la actitud del hablante, y mostrando cuál es la relación del sujeto con su enunciado. El hecho interactivo de la comunicación humana manifiesta aspectos relevantes como su constitución, emisión; intencionalidad, etc., es una relación dialéctica entre emisor y receptor, embarcados en la díada conversacional. El estudio de los actos de lenguaje viene a poner de manifiesto esta relación, pues las recurrencias de las estructuras modales son una manera de interpretar la vida interior del individuo con sus conflictos y posiciones.

Para acercarnos a las actitudes socio-ideológicas de los hablantes hemos establecido tres bloques de análisis:

3.1.1. Análisis de los actos de lenguaje, en virtud del que se puede observar la cooperación conversacional y la actitud de vigilancia mutua, por lo que se puede deducir la actitud de participación de los interlocutores.

El principio de cooperación conversacional es uno de los procesos sociales universales. El acto de interacción, incluso en sus más cortos intercambios demanda cierta cooperación para que el acto comunicativo se pueda llevar a cabo; este principio es esencial a la entrevista, pues por él, el entrevistador intenta ayudar (acto de ayuda), clarificar (acto de información), etc. Hay otra serie de actos realizados por ambos interlocutores que favorecen la cooperación, como el acto confirmativo, con el que un interlocutor asiente, o bien confirma la comprensión de lo que el otro está diciendo, con expresiones como: "si", " $M m^{\prime \prime}$. A veces se puede buscar el refrendo (acto de refrendo) con el que se intenta buscar el apoyo o el consentimiento de quien escucha.

La actitud de vigilancia mutua es un factor importante, cuya validez se observa al analizar el discurso del entrevistado, quien llega a utilizar frases, fragmentos o palabras iguales a las contenidas en la intervención del entrevistador, lo que denota una reacción en cierto sentido escolar. También se da el caso de que algunos elementos remáticos utilizados por los entrevistados son retomados por el encuestador para afianzar mejor la comprensión de la conversación, o porque atraen una información valiosa. Esto puede dar lugar a que se alargue el intercambio, o incluso hasta que se produzca una desviación del cuestionario, debido a las necesidades interactivas de la entrevista.

3.1.2. Estudio de la enunciación. Mediante la enunciación el hombre se constituye en 
sujeto de su discurso, aportando datos que configuran su actitud en el enunciado. Hay una serie de elementos que conforman el dominio de la subjetividad aunando los actos de lenguaje, coordenadas intencionales, con las coordenadas materiales representadas en un espacio "hic" (aquí) y un tiempo "nunc" (ahora). Otros signos mediante los que el sujeto se sitúa en su discurso son los pronombres personales, que cumplen una función deíctica mostrando la relación interlocutiva. Con estas marcas lingüísticas, el hablante manifiesta actitudes como la solidaridad/insolidaridad, la conciencia de grupo, la categorización de la realidad, la actitud generacional, las estrategias persuasivas, que están condicionadas culturalmente y vienen también dadas por el contexto social en que se desarrolla la comunicación, según los receptores tengan una edad u otra y sobre todo por la ideología y la forma de ver el mundo.

3.1.3. Funciones pragmáticas y estudio del léxico. Por último analizaremos las funciones pragmáticas y el léxico, en el que aparecen determinados registros que presentan términos relevantes de ciertos ámbitos léxicos. A través de las funciones pragmáticas, sobre todo de la Función Foco, podemos deducir la visión de la realidad del hablante, teniendo en cuenta la forma en la que presenta los problemas en su discurso.

El contexto en el que realizan las grabaciones es un lugar cerrado, un aula del centro, algunas veces se producen interferencias, ruidos externos procedentes de la calle o del teléfono. El conocimiento que tenemos del contexto viene dado por la cinta magnetofónica con la que hemos trabajado. Para la realización del trabajo ha sido necesario pasar los textos de orales a escritos, bajo unos criterios de transcripción personales, con la intención de poner de manifiesto la lengua oral, de uso; nos ha interesado mostrar lo que se oye: repeticiones, risas, balbuceos, pausas, elementos paralingüísticos.

Los sujetos entrevistados son alumnos de BUP, delegados de curso, el Locutor 2 pertenece a un centro público, y el Locutor 3 a un centro privado, mientras que el entrevistador es el mismo en las dos entrevistas (Locutor I). Nos interesa destacar que las actitudes que hemos deducido no tienen pretensiones de generalidad, ya que pueden estar motivadas por diferentes factores, siendo el principal el contexto en el que se desarrolla la entrevista y las características formales específicas que impone este tipo de relación comunicativa, que condiciona sobremanera la actitud de los participàntes y sus intervenciones. Ahora bien, estas actitudes nos servirán para determinar cuales son sus posiciones, en un espacio concreto y en un momento prciso de sus vidas, y serán un detonante, parte integrante de su comportamiento en general, expresado de esta manera en estos intercambios, aunque no hay que olvidar que la entrevista está limitada por el recorrido que separa la opinión asumida en el momento de su realización y el comportamiento en la vida cotidiana.

A continuación presentaremos el análisis de ambas entrevistas ${ }^{2}$.

\section{Análisis de las entrevistas}

\subsection{Texto 1}

Este texto se divide en catorce intercambios en los que los participantes interactúan.

\footnotetext{
${ }^{2}$ Hemos denominado a la entrevista realizada al Locutor 2 (L.2), Texto 1 y a la del Locutor 3 (L..3), Texto
} 2. 
Por tratarse de una entrevista, texto estructurado bajo la tensión pregunta/respuesta, el acto de lenguaje más usual en las intervenciones del entrevistador, Locutor 1 , es el acto interrogativo y en las del Locutor 2, el asertivo, aunque estas expectativas pueden modificarse, pues no siempre utilizan estos actos en sus intervenciones.

Una de las características que nos van a dar la clave de la relación interactiva será observar el uso de los determinados actos de lenguaje que dichos por un locutor influyen decididamente en el otro a la hora de plantear su enunciado; en este caso el encuestador condiciona al Locutor 2, precisamnte por la relación de poder que tiene lugar entre él, persona adulta que lleva las riendas del acto comunicativo y el encuestado, quien reconoce en su interlocutor la autoridad.

El L.2 se expresa fundamentalmente con actos asertivos aunque velados por la afirmación negación como creencia: "yo creo que...", "yo no creo que...". Este uso es una forma de paliar la responsabilidad que tiene la aserción pura. Un dato significativo es que L.2 utiliza la afirmación como creencia cada vez que el encuestador se sirve del verbo creer, menos en una ocasión en la que aserta pero inmediatamente busca el refrendo del L.1:

(IX, 3-4)

L.1: ¿Pero tú crees que tiene eco?mo sea que la juventud está por asociarse?

L.2: $\mathrm{Mm}$... la juventud en su mayoría pasa de estas cosas,...hay una minoría de jóvenes ino? que se asocian..."

La aserción puede ser reforzada por verbos como ver, conocer, saber, que arraigan su discurso en una experiencia muy personal:

$(\mathrm{I}, 2)$

L.2: "...la juventud, digo, mayoritariamente, la que yo conozco, principalmente...".

La cooperación conversacional se ve reforzada por actos como el confirmativo que no sólo aparece en el discurso del L.2 sino que también es usado por el entrevistador:

(III, 1)

L.2.: "...entonces, claro, el joven piensa que no es útil, entonces se siente marginado y ---"

L.1: "Sí, ¿tú este tema..."

En los actos informativos vemos la intención del L.1 por clarificar, informar con el fin de hacer más fácil la comprensión de la pregunta, puesto que es el entrevistador el locutor más capacitado para realizarlos según las leyes de la entrevista:

$(\mathrm{V}, 3)$

L.1: "¿y qué tipo de actividades pueden ser?, o sea la juventud, en general, ¿no? para esa que parece apática y para $\mathrm{Mm}$..."

La cooperación se observa también en los distintos intentos por parte del L.1, para ayudar a su interlocutor en los momentos en los que nota vacilaciones, olvido del tema central, etc. 
$(\mathrm{XI}, 7)$

L.2: "y pero no creo que llegue a un grado de conciencia-"

L.1: "= la continuidad concretamente es lo que tú ves más flojo ¿no?"

Suele ocurrir que el acto de refrendo en las intervenciones del L.1 aparecen tras un acto informativo:

(VIII,1)

L.1: "=Sí,tú imagínate un grupo de jóvenes, el tuyo, el de tus amigos ¿no? Mm... si pidiérais unos locales ¿para qué los pediríais?"

Los actos de refrendo son muy usuales en la expresión del entrevistado, ya que continuamente intenta corroborar si el entrevistador está de acuerdo con aquello que declara, por lo que se convieten en una estrategia persuasiva:

(IX,2)

L.2: "...la juventud está empezando a tomar voz lno? en las instituciones..."

$(\mathrm{XII}, 2)$

L.2: "...con más gente de la juventud ¿no?, yo creo que hasta la gente que pasa de to ino? Mm..."

La actitud de vigilancia mutua vendría dada en el Texto 1, en cuanto al L.2 se refiere por los actos recordatorios, con los que realiza repeticiones de frases enteras, fragmentos o palabras iguales a las contenidas en las intervenciones del L. 1; así L.2 se mantiene dentro de esquemas fijados por la "autoridad":

$(I, 2)$

L.2: "...Mm...no se, "problemas y actitudes de los jóvenes ante el trabajo, yo creo que..."

$(\mathrm{II}, 6)$

l.2: "hombre, de la propia juventud no, porque la juventud no tiene dinero..." (VIII,3)

L.2: "=Hombre que compartan las mismas inquietudes yo creo que sí..."

Puede darse el caso de que los elementos remáticos empleados por el entrevistado sean incorporados por el L.1 en sus intervenciones, para perfilar mejor la información que considera valiosa; cuando esto ocurre el intercambio se alarga o se distancian de las directrices temáticas marcadas por el cuestionario:

L.2: "...Mm...piensa que cuando acabe los estudios va a tener trabajo, Mm...pero yo creo..."

L. I: "¿tú crees que de verdad está con, piensa que va a encontrar trabajo la juventud estudiante?"

El engarce de las intervenciones se realiza por una serie de palabras o frases que al encuestador le dan pistas para profundizar en el tema de su pregunta o simplemente para completarla: 


\section{(VI,2-3)}

L.2: "es un tipo de evasión pasiva, o sea que tú oyes música-7 tú-7ves..."

L.1: "Bien entonces Mm...itú crees que la gente en todo ese tinglao se divierte, es decir, en esa evasión pasiva o al final..."

Así vemos que durante toda la entrevista se produce un acoplamiento entre el decir de los interlocutores. Cuando al L.2 se le pide opinión acerca de la posible solución a los problemas que se le presentan a la juventud, ofrece su solución con actos desiderativos, quedando su iontervención a la sombra de lo que debería ser, bajo la fragilidad de un futuro incierto, por lo que no es extraño que estos actos aparezcan junto a actos dubitativos:

L.2: "...Mm..tendrian si hubieran medios para esta gente pues yo que se, aparte de divertirse ellos podían sacar provecho..."

Los actos dubitativos animan toda la entrevista, en el discurso del L.1 emergen cuando intenta exponer con claridad, pero son más abundantes en el discurso del L.2 no sólo porque son más extensas sino también porque está menos acostumbrado al espacio del diálogo creado en la entrevista, a la vez que la tensión producida por el hecho de saber que se está grabando lo que dice hace que el acto dubitativo se convierta en una forma de autocontrol sobre su discurso.

Los actos interrogativos son cuantiosos en las intervenciones del L.1, provocado por la propia estructura de la entrevista, por el contrario, el L.2 sólo realiza un acto interrogativo, aunque la fuerza locucionaria de éste, excede el alcance de la mera interrogación ya que no demanda información sino que es un recurso con el que retarda su participación mientras que piensa mejor lo que va a decir:

\section{(VIII,2)}

L.2: "¿Para qué lo pediríamos?, puesmique qué haríamos? pues yo que se, cantidad de cosas..."

Cada acto individual de apropiación de la lengua constituye un dato para la manifestación de formas específicas, cuya función es poner al locutor en íntima y constante relación con su enunciado. La relación establecida por la entrevista arraiga a los interlocutores en un espacio muy concreto, el lugar donde se realiza, contexto que la determina necesariamente, ahoara bien, el L.1 no hace referencia alguna a este lugar, sin embargo sí hace hincapié en que el L.2 se sitúa en su ambiente cotidiano del cual pretende obtener información. El L.2 además de nombrar la ciudad en la que vive (Murcia) menciona otros espacios entre ellos el centro en el que estudia: "...o en el sitio donde estoy...a mi centro por ejemplo...". Siempre circunscribe el espacio en el que se desarrolla la acción, referida a la experiencia concreta:

L.2: "luego yo en el sector que me muevo, entre la juventud estudiante..."

Los deícticos espaciales "ahí" y "aquí" son utilizados con imprecisión, suponen una forma de marcar el espacio donde se realizan diferentes actividades: $(1,2)$, "...trabajamos en verano de vez en cuando por ahî", o $(\mathrm{VII}, 4)$, "... yo creo que ahi ya no funciona..."; algunas veces este adverbio sirve de muletilla que aligera el discurso y le permite no ser 
demasiado preciso cuando no lo desea o cuando los datos se deducen del contexto. L.2 tiene una forma muy peculiar de representar en su discurso la realidad, en la que sitúa dos grupos socialmente enfrentados: "los de ABAJO" en el que coloca a jóvenes estudiantes, trabajadores, parados, marginados, etc., y a "los de ARRIBA", bloque que engloba a empresarios, administración, gobierno, etc., con lo cual podemos extraer una ideología de corte marxista:

\section{$(\mathrm{VI}, 4)$}

L.2: "es una evasión que le meten ahí y que claro $\mathrm{Mm}$...Mm...la gente que está arriba la promociona ino?"

$(\mathrm{XIII}, 2)$

L.2: "la droga que...que en realidad se mueve desde arriba, no la mueven pequeños...pequeños camellos"

Ya hemos señalado que todo enunciado se sitúa en un tiempo presente "nunc" desde el que se rememora el pasado o se visualiza el futuro. Por las peculiaridades del texto que estudiamos la presencia del tiempo presente y del pretérito perfecto es muy fuerte, junto con la aparición de adverbios y frases adverbiales del tipo: "hoy", "todos los días", "siempre": $(I, 2)$, "...el ejemplo lo tenemos tos los días en la calle" $(\mathrm{XIII}, 4)$, "...ahora yo creo a donde está llegando es a los jóvenes...".

Podemos observar que el L.2 estructura el tiempo según los ciclos académicos: tiempo lectivo, otoño-invierno/tiempo no lectivo verano.

En el paso del "Yo" al "nosotros" vemos la conciencia de pertenencia a un grupo, que además se manifiesta por la cercanía a los problemas e inquietudes que les caracteriza, con "nosotros" señala a la juventud estudiante:

$(\mathrm{I}, 6)$

L.2: "Luego yo en el sector que me muevo, entre la juventud estudiante...cuando van pasando los años...se....se van dando cuenta de esto...y de qué en realidad donde están es una fábrica de parados..."

Pero el "nosotros" abarca también el mundo de la juventud trabajadora y parada con el que él se relaciona por su situación de trabajador eventual en los veranos:

(III,2)

L.2: "...en la empresa privada no creo que esté la solución...los empresarios son los que tratan de sacarnos el pringue..."

Las estrategias discursivas son empleadas tanto por el encuestador como por el encuestado. Una estrategia es la dramatización de situaciones, a través de actos ejemplificativo-asertivos, con los que el locutor introduce en su discurso el discurso de otro sujeto:

$(\mathrm{X}, 4)$

L.2: "dicen:"pā que voy a asociarme a ninguna cosa, yo tengo mi evasión propia y ya está..."

$(\mathrm{VI}, 1)$

L.1: "...y la gente dice:"¿jo, que rollo tú, que paliza..." 
Otro de los problemas que nos pueden ayudar a dilucidar las actitudes de los participantes es el estudio de las funciones pragmáticas. Entre las que nos interesa especialmente la función Foco. Función ejercitada por aquellos constituyentes que sean información no compartida por ambos interlocutores. Tanto la función Tópico como la función Foco colaboran en el desarrollo de la información que se quiere dar a conocer. A pesar de que la función foco se presenta como la principal responsable del avance informativo en la entrevista. Hay casos en los que los elementos dichos por el L.2 se llevan al L.1 a realizar otras preguntas:

$(\mathrm{XII}, 2)$

L.2: "...y el contacto con la naturaleza..."

L.1: "Sí, pero, sin embargo los movimientos ecologistas y cosas de esas"

En cuanto al léxico hay que destacar que el L.2 se expresa con registros pertenecientes a un argot juvenil lo cual demuestra la existencia de un ambiente relajado, en el que no cuida su dicción pues se siente en confianza, por lo que aparecen expresiones como: "to el mogollón este", "currando en verano", "no le dan al coco", "necesitamos unas cuantas pelas", etc; hay expresiones que se convierten en muletillas: "cantidad de pelas", "cantidad de cosas". En otras ocasiones recoge expresiones propias de un lenguaje coloquial de baja extracción: "darle la larga", "darse ellos el lote", "que de el callo", etc., también se refleja el mundo de la droga cuyos problemas le preocupan sobremanera: "pequeños camellos", "se siente maryinăo".

\subsection{Texto 2}

El Texto 2 está formado por trece intercambios y en él notamos cierta violación de los patrones estructurales de la entrevista, en la medida en que lo esperado en un acto comunicativo de esta índole es que la mayoría de los actos interrogativos sean utilizados por el entrevistador y no por el entrevistado. L.3 realiza bastantes actos interrogativos y el L.1 ha de hacer a menudo actos informativos, de ayuda, para conseguir que responda con cierta claridad de la que se carece casi siempre; además las aserciones del L.3 suelen ser muy breves, limitándose a actos de creencia sin expresiones que le supongan riesgo alguno o le puedan inducir a equivocarse, por lo que no desarrolla apenas las ideas contenidas en las preguntas, aunque habría que destacar que precisamente por esta actitud defensiva intenta sujetar sus aserciones a la realidad mediante el verbo ver con el fín de dotar su discurso de mayor veracidad, colocándolas "ad oculos", para ligar asî sus afirmaciones a la experiencia:

$(\mathrm{VI}, 18)$

L.3: "=No, ahora ya se ve más interés /por.../ porque te sale a ti mismo..." $(\mathrm{X}, 2)$

L.3: "no es que sea, y he visto que sea, son grupos que se forman..."

A pesar de este empeño de expresar lo que conoce con este verbo, sus aserciones y los ejemplos que expone, no son lo suficiente significativos, pues presenta los acontecimientos de una manera distante, sin tener en cuenta factores importantes de la vida cotidiana, y su intervención más larga es realizada al contar una experiencia de paro vivida por un hermano suyo: 
L.3: "...aunque tengo una experiencia en mi casa con un hermano mío, que/había termināo.../que habia dejāo a medio la carrera universitaria y no tenía ningún...ningún trabajo, ni estudiaba ni hacía nada y se le veía pues como ino?, perdido...".

Pero tampoco es ésta una aserción segura sino que busca el refrendo del L.1, quien pasará a plantearle otra pregunta con el fin de no caer en problemas de alcance hogareño.

El principio de cooperación conversacional, necesario para el desarrollo de todo acto comunicativo oral en el que los interlocutores se sitúan cara-a-cara, en este texto tiene gran importancia, pues debido a la actitud del entrevistado, el entrevistador necesita hacer uso de actos informativos y de ayuda, ya que el L.3 no mantiene una relación de participación, de cooperación activa. Normalmente respeta el lugar de posible transición ${ }^{3}$, cuando no to hace es debido a que el L.1 ha emitido un acto confirmativo ante la reducción del tono de voz o la duda del L.3 o porque éste haya realizado un acto de refrendo, de manera que el L.1 tras el acto confirmativo, continúa hablandio para lo que utiliza actos de ayuda y el L.3 apoya la intervención del L.1 con actos confirmativos o de creencia muy breves, produciéndose una serie de intervenciones cortas y encadenadas rápidamente que no cumplen las expectativas contenidas en el seno del acto interrogativo.

L..3: "...¿ino? prefieren, no sé, buscar una solución y actuar no ---"

L.3: " = No, no creo-"

$(\mathrm{I}, 7)$

L.3: "o sea, ¿que se piensa que tiene solución?"

El esfuerzo del entrevistador es apreciable y en todo momento intenta facilitar el terreno, con cierto tono paternalista, para lograr que disminuya la tensión en la relación dialógica, llegando incluso a cantar unos fragmentos de una conocida canción para atraer la atención y ganarse la confianza del L.3:

(VI, 2)

L.3: "=itiempo libre?-"

$(\mathrm{VI}, 3)$

L. 1: "=Como dice ese en su canción ((canta)) "¿a qué dedica el tiempo libre?" ¿eh?"

Los actos confirmativos y de refrendo son realizados tanto por el L. 1 como por el L.3, siendo una muestra clara de la cooperación conversacional, ejerciendo la función de "puentes" trazados entre los diferentes interlocutores. La mayoría de los actos confirmativos del discurso del L.1 no respetan el lugar de posible transición, sirviendo de refuerzo interactivo para la intervención del L.3. Además el entrevistador consciente del alejamiento del L. 3 realiza abundantes actos de refrendo, con la intencionalidad de ser entendido y de que no se derive hacia otro foco de atención.

${ }^{3}$ Tal y como indica Ma Luisa Gurruchaga (1981:214), "el punto en que termina una 'unidad lipo' constit uye lo que llaman litgar de posible transición (transsition-relevance place), y ahí es donde se produce normalmente el cambio de interlocutor. El oyente puede prever, desde su comienzo, cuál será la extensión aproximada de la 'unidad tipo' en curso, anticipando así la llegada del lugar de posible transición". 
La actitud de vigilancia mutua caracteriza toda la entrevista, podemos advertirla en los actos recordatorios, que no sólo cumplen una función que rememora lo dicho por el L.1, sino que también sirven para crear unos instantes en los que a la vez que se repite una frase se piensa lo que se va a decir, en este caso se deduce fácilmente por la pausa que se produce a continuación del acto recordatorio y de la repetición:

\author{
$(\mathrm{VII}, 1)$ \\ L.1: "Mm...y ¿tú qué crees que pueden hacer las organizaciones juveniles o la \\ administración o los colegios, para darle a la juventud elementos que le llenen \\ bien su tiempo libre?, ¿qué podrían hacer?" \\ L.3: "¿Qué podrían hacer? (8 seg.) no se ma...a que/ eso.../esas artes...artes \\ plásticas por llamarlas así-"
}

Pocas veces el entrevistador utiliza elementos con valor remático dichas por el L.3, sino que las palabras del entrevistado inspiran al L.l quien cree conveniente cerrar el sentido de la pregunta colaborando con su participación, por lo que las intervenciones del L.1, en este caso tienen un valor de "relleno" o "reparador", tal y como observamos en el ejemplo siguiente:
$(\mathrm{X}, 6-7)$
L.3: "al mismo sitio pero por caminos distintos ---"
L.1: "o sea que están cerrados ino?"

Los actos dubitativos son un dato importante en las intervenciones del L.3, mostrando un estado de nerviosismo, indecisión probablemente provocada por el desconocimiento sobre el tema. El entrevistador duda sobre todo tras haber realizado un acto inetrrogativo que su interlocutor no ha entendido, lo que puede abocarle a la duda por no saber cómo plantear la cuestión para ser mejor interpretado o llega a hacer una pausa más larga como ocurre en el intercambio (II,1): "Sí (5 seg.) iconoces algo del mundo de la gente parada?".

El L.3 hace pocas referencias al espacio, debido al distanciamiento que venimos observando en su discurso, que le lleva a mantenerse al margen de determinadas realidades como el paro, la problemática de la juventud trabajadora, etc.

El L.1 plantea sus cuestiones en tiempo presente que se refuerza con expresiones como ahora mismo, con la que centra el problema del que se trata justo en el momento en el que se realiza la entrevista: (VIII, 9): "Y itú crees que la juventud está ahora mismo por aceptar que venga gente a dirigirla?". El L.3 también utiliza el presente junto con el pretérito perfecto, tiempo ligado al discurso autobiográfico. El adverbio ahora es usado por el L.3 cuando dramatiza situaciones para dar mayor verosimilitud y énfasis: $(X I, 4)$ : "Mm...llega un momento en que es, bueno, "ahora hago esto, como no va apasar nada", pues, bueno, "si ahora me pincho", "si ahora, paso de esto, paso de lo otro", no es una preocupación ---"

El paso del "Yo" al "Nosotros" se da en las intervenciones del L.3 al incidir en una problemática de su vida, en temas como la situación de apatía, las salidas laborales al acabar la carrera, las amistades, etc., pero nunca con cuestiones relacionadas con jóvenes trabajadores, en paro, o gente alejada del mundo estudiantil: 
$(1,2)$

L.3: "Es que no es...es una competitividad total, siempre hay grupos que se apoyan unos a otros...a lo mejor con un compañero que te llevas bien, que...que es un amigo tuyo pues sí, lo apoyas... siempre tiendes a sacar a mejorarte a ti mismo, a ser algo más, a subir y ves a los demás por arriba y tienes que estar por encima, siempre es competitivo-"

El individualismo lleva al entrevistado a plantear la relación con el resto de su grupo de forma competitiva, y por consiguiente la relación "Yo/Nosotros" crece marcando las diferencias, justificando la actitud de competencia por el momento histórico que le ha tocado vivir. No tiene una conciencia de grupo que le haga partícipe de unas experiencias comunes, que le lleven hacia la solidaridad, como vemos en la siguiente declaración: $(I I, 8)$, "sí, intentas ayudar a los demás un poco más, pero lo principal eres tú"; el mismo individualismo provoca que para hablar de ciertas situaciones por las que atraviesa la juventud, lo haga madiante la tercera persona, o con marcas de impersonalidad producidas por \Ise \i: "Se piensa, claro, se puede salir", "no se suele hacer".

La función pragmática Foco es asignada a la predicación y nos muestra la organización que los hablantes imponen sobre sus discursos. Los elementos de esta función que hallamos en las intervenciones del L.1, manifiestan aquellos núcleos sobre los que se reclama la atención para hacer que avance la encuesta y coinciden con los temas generales del cuestionario. Algunos de los constituyentes con función Foco muestran una actitud poco autónoma, más bien se colocan como "buen criterio de autoridad", y así por ejemplo a la hora de buscar las causas de la apatía que muestran, declara: "...bueno hemos estado viendo que se nos han dado las cosas muy fáciles...". Intenta poner de manifiesto la importancia de la figura del consejero: "...como si fueran digamos consejos, consejos, $\mathrm{Mm}$... dar consejos, no como líderes...", con lo que las actuaciones de los jóvenes quedarían dirigidas; centra todo el problema del paro en torno al aumento de población, como si su respuesta estuviera extraída de su libro de geografía, con un tono objetivo poco adecuado para una situación que agobia al joven en general, en ningún elemento coloca como Foco elementos que hagan referencia a cuestiones políticas, lacras sociales, etc.

El lenguaje utilizado por el L.3 podríamos caracterizarlo por la "indefinición", atenúa en todo momento el efecto de sus palabras mediante términos de significación menos tajante de la que correspondería, bien por miedo, humildad, cortesía u otros factores. No emplea "tic" o "muletillas" lingüísticas propias de los hablantes de su edad, o términos expresivos pertenecientes a un argot concreto, y cuando lo hace, (intercambio XI,4) es reproduciendo el decir de otros jóvenes: "me pincho...", "paso de esto...".

El entrevistador intenta acercarse a través de expresiones distendidas que en su opinión le sitúan más cerca del entrevistado, tales como: "que no dé más el follón", "de lo que te dé la gana", etc.

\section{Deducción de actitudes a partir de la comparación de las encuestas}

Los sujetos, cuyos discursos vamos a comparar, tienen mucho más en común que distinto, puesto que son jóvenes inmersos en una sociedad que no ofrece demasiadas ofertas, para los que el futuro no presenta un perfil esperanzador.

A pesar de que la interacción comunicativa es un proceso que consiste en la transmisión tanto de un flujo verbal como de una serie de componentes somáticos, organizados en la acción producida por dos participantes, esta relación diádica no siempre 
se produce con la misma participación de los sujetos, ni hay igual equilibrio de fuerzas, depende en gran medida de las actitudes de los sujetos embarcados en la conversación, el que consigan igualar sus posiciones.

Uno de los factores fundamentales para que un acto interactivo se produzca con normalidad, es tener en cuenta al otro, situándose frente a un Tú, pero siempre sintiéndolo como un Yo con capacidad de emitir y recibir un mensaje, con capacidad y derecho al diálogo. En la entrevista se establece la interacción a partir del cuestionario, "trampolín desde el que se despliega el contacto entre los participantes. El modo de tener en cuenta al "otro" varía de una entrevista a otra, por parte de los entrevistados, mientras que el L.1 mantiene una actitud similar en ambos textos, haciendo continua referencia a sus interlocutores por medio del pronombre "tú": $(1,3)$ "¿Tú ves en esto una situación de dependencia?". La relación establecida por el L.2 es más personal, incorpora directamente al encuestador en su discurso y llama su atención con expresiones del tipo : "te digo", "lo que te decía antes". Mientras que L.3 en ningún momento se dirige al entrevistador, ni tan siquiera cuando hace referencia a lo que ha dicho: "...es algo que he dicho antes...". El tener en cuenta en el discurso propio al L.1 es una forma de camaradería, de mostrar confianza y dejar clara su vinculación mediante el diálogo, que tiene como función hacer al otro co-partícipe. La causa por la que L.3 no lo hace puede ser su carácter introvertido que le obliga a estar encerrado en sí mismo.

La postura participativa del L.2 viene dada por el hecho de que no respeta el lugar de posible transición, sino que ante la pregunta, aventura la respuesta con rapidez, al contrario L.3 sí los respeta y cuando no lo hace es porque el L.1 se ha entrometido en su intervención con un acto de ayuda o confirmativo, ante lo que L.3 contesta con actos confirmativos: "Sî", o de creencia: "Sí, creo que sî", produciéndose una red de intervenciones muy breves, actuando L.1 como co-autor de las respuestas por la falta de ideas, nerviosismo, silencios, o las dudas del entrevistado:

(IX, 2-3-4-5-6-7)

L.2: "no, yo creo que sí se preocupan, de hecho ahora mismo, esta entrevista es símbolo de ello -

L.1: "=Sî"

L.3: "sí, sí lo veo se preocupan-

L.1: "= organizando campeonatos, organizando cosas, Mm..."

L.3: "Sí, sí, vamos, a mí me ha gustāo bastante eso, han organizāo bastantes actividades para....para la juventud -

L.1: "=o sea que están viendo que hay renovación..."

Las intervenciones del L.2 son más ágiles, las pausas son las usuales para poder hablar con normalidad, marcadas por "coma", "punto y coma" y "punto", sin embargo L.3 realiza pausas de mayor duración, de tres y ocho segundos, sobre todo cuando tiene que dar una respuesta que exige creatividad, buscar soluciones, justificar su actitud, etc.

El análisis de los actos de lenguaje nos ayuda a deducir la actitud de mayor o menor participación. L.2 sólo realiza un acto interrogativo pues no suele tener problemas para entender las preguntas, mostrando en sus aserciones un conocimiento teórico y práctico del tema que posibilita la pronta respuesta: responde con largas aserciones en las que pone ejemplos, opinando aún a riesgo de equivocarse, e incluso nombra datos para dotar sus aserciones de cierto rigor.

Los actos de refrendo junto con los confirmativos tienen gran importancia en el mecanismo de cooperación conversacional, ya que muestran el vínculo interactivo. Estos 
actos vienen a ser "puentes" trazados para facilitar el intercambio de información que supone todo acto comunicativo. L.3 no busca el refrendo del entrevistador más que en dos ocasiones: una al afirmar que la juventud no vive la situación del paro con angustia, $(1,4)$, "io con angustia? no, no creo que haya nadie que...que vea esto muy...muy duro, ino? prefieren, no sé buscar una solución y actuar, no ---", y la otra, al contar la experiencia de paro de un hermano, $(H, 4)$. Hace un uso abundante de los actos interrogativos (siete veces), pues con frecuencia tiene problemas para entender el alcance de las preguntas, lo que provoca un encadenamiento de intervenciones. El hecho de que el L.3 no necesite decir actos de refrendo en alguna ocasión parece ser que es porque considera que sus aserciones son verdades incuestionables, pero la mayoría de las veces la misma timidez impide que mantenga una relación distendida y de mutuo apoyo entre él y el L.l, propiciada por el acto de refrendo.

Teniendo en cuenta el desarrollo del principio de cooperación conversacional, vemos como los actos de ayuda e informativos son más frecuentes en el Texto 2 que en el Texto 1: frente a cuatro actos de ayuda y ocho informativos del primer texto, el Texto 2 presenta once de ayuda y doce informativos. Estos actos en el Texto 2 vienen a paliar las deficiencias que en opinión del L.1 padecen las intervenciones del L.3, cumpliendo una función de "relleno" y sirven para cerrar el sentido de los actos interrogativos planteados por el entrevistador, cubriendo éste la información que se requería del L.3.

Los actos dubitativos propios de la expresión oral, eminentemente espontánea, son marcas del nerviosismo o de dudas, entre otros factores; este tipo de actos son frecuentes en el Texto 1, aparecen en todas las intervenciones excepto en siete que son más breves y en las que la dicción es más pausada y menos expresiva. El L.1 realiza más actos dubitativos con el L.3 que con el L.2, pues éste suele entender mejor las cuestiones con lo que el entrevistador plantea su enunciado tal cual lo lleva escrito en el cuestionario, sin modificar nada por lo que no duda a la hora de comunicar su información.

Mediante la enunciación el sujeto hablante marca subjetivamente su enunciado. Cada acto individual de apropiación de la lengua constituye un dato para la manifestación de formas específicas, cuya función es poner al locutor en íntima y constante relación con su acto de comunicación.

La manera en la que un individuo presenta el espacio en su discurso siempre es significativa, dado que muestra desde donde se sitúa el mismo. Ambos sujetos hacen referencia a la ciudad de Murcia, pero la forma de plantear el espacio es distinta: $(\operatorname{IV}, 2)$ L.2: "ahora yo creo que...que esto no se da en Murcia....", a su vez el L.3 declara. (VI,4) "...a dar una vuelta por...por Murcia".

L.3 circunscribe la referencia espacial a su grupo de amigos y a su entorno familiar, sus coordenadas espaciales son "hogareñas", no nombra lugares concretos, todo queda en un "dar una vuelta por ahí". L.2 va más allá del ambiente familiar, delimita el espacio en el que se mueve, que es tanto el mundo del trabajo como el del estudio, con ejemplos vivos tomados de la calle; su conocimiento es por cercanía a los hechos. Sin embargo L.3 reconoce su alejamiento del mundo del trabajo o de la marginación, su contacto se limita a su grupo de amigos y compañeros de estudio. El L.2 mediante el adverbio ahí señala lugares en los que la juventud se relaciona, "casa de juventud", "tascas y pubs", con lo que concreta el espacio haciéndolo más cotidiano.

El uso de los pronombres personales nos da la clave de la consciencia de grupo, que advertimos en el deslizamiento del "Yo" al "Nosotros". El L.3 se siente dentro de un colectivo reducido, el de la gente que estudia, y así lo afirma: (II,4), "No, no se, la...la mayoría de la gente con la que yo más me relaciono, está en...en colegios y eso, está estudiando". No menciona otros colectivos de jóvenes, ni conoce de cerca los problemas 
que pueden tener y atribuye el que muchos de ellos estén atrapados por la droga, la delincuencia, la apatía, etc., a la "falta de ideales", actitud que muestra su poca autonomía a la hora de opinar, repitiendo concepciones prestadas de los adultos, en este caso parciales por no responder a toda la realidad del problema:

\section{$(\mathrm{XI}, 8)$}

L.3: "Claro, sería mucho...mucho mejor, desde un principio. Se conserva por lo que luchas, o sea por lo que es una cosa, no por lo que luchas- $(\mathrm{Mm})$ vamos que...que tuvieran/un.../unas barreras, unos ideales, que es lo que creo hace falta; que nadie se los plantea..."

Así por ejemplo, silencia los factores socioeconómicos, ambientales y culturales, cuya incidencia no es nada desdeñable en la actitud de la juventud, que se ve cogida por la desgana que aumenta con la falta de alternativas, objetivos, etc.

La relación con su propio grupo está marcada por un fuerte individualismo, como él mismo indica, "lo principal eres tú", (III,8,10), "siempre tiendes a individualizarte, a ser tú mismo ( 3 seg.) vamos a que por lo menos no te pisen". Su actitus es competitiva incluso con los miembros de su grupo:

\section{$(\mathrm{IV}, 4)$}

L.3: "...siempre tiendes a sacar, a mejorarte a ti mismo, a ser algo más, asubir y...y ves a los demás por arriba y tienes que estar por encima, siempre es competitivo".

La actitud del L.2 frente al grupo es distinta, se siente dentro de un colectivo amplio, en el que incluye también a la juventud trabajadora, parada, marginada. Su conciencia social es mayor, el paro afecta no sólo a la juventud que busca trabajo y no encuantra, sino que también amenaza a quienes realizan estudios por la escasez de ofertas laborales al terminar las diferentes carreras universitarias, siendo en su opinión la universidad: "una fábrica de parados".

El individualismo del L.3 es mayor que el expresado por el L.2. No cree en el grupo, mientras que el L.2 cree en la colectividad y defiende que los jóvenes para buscar soluciones han de mantenerse unidos y aunque ambos tienen la sensación de estar ante un futuro incierto, L.2 cree en el diálogo, e intenta llevarlo a la práctica: $(X I, 4), L .2:$ " = se contagia un poquillo, ¿no? pero yo creo que...que como hacen ellos también hay que ver la posibilidad de llegar a ellos...". L.2 analiza los problemas de manera crítica, desaprueba la postura de los empresarios, quienes explotan al joven a través de la economía sumergida: $(111,2)$, "Hombre ${ }_{\text {yo }}$ creo ${ }^{\star}$ que en la empresa privada y...y to esta gente, los empresarios son los que tratan de sacarnos el pringue...". La postura de la administración también es criticada, segán su opinión, las salidas que oferta no están al alcance de los jóvenes que han de empezar desde cero. Por el contrario el L.3 no habla de problemas económicos ni políticos. La actitud ideológica puede ser deducida a partir de los discursos, según el modo en el que estructuran la realidad. El L.2 presenta la realidad escindida en dos bloques enfrentados: los de ABAJO y los de ARRIBA, como hemos señalado con anterioridad; en este análisis él se coloca en el grupo de los de ABAJO, grupo que en su 
opinión es explotado por el otro, aflorando de este modo una ideología de corte marxista. La actitud ante las salidas en el futuro tampoco es la misma. La capacidad de lucha mueve el ánimo del L.2, sin embargo el L.3 se hunde en la propia oscuridad del momento histórico que se le avecina, y ante esta realidad no opta por buscar salidas conjuntas con los jóvenes que tienen iguales problemas, antes bien, los ve como opositores a los que hay que vencer y superar, para estar por encima de ellos, a los que hay que dejar atrás, para encontrar en solitario su principal meta: un puesto de trabajo rentable. Los siguientes cuadros pueden ser muestra de las dos actitudes:

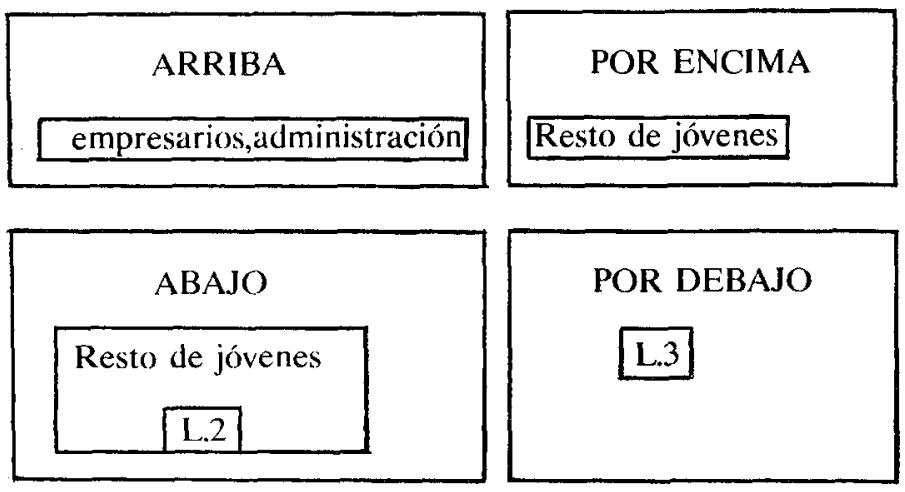

Los datos deducidos a partir del análisis de las funciones pragmáticas corroboran y apoyan las actitudes que venimos atribuyendo a estos hablantes, a través de ellas van presentando en su discurso los problemas, que en cada entrevista tienen un desarrollo particular. De todas las funciones pragmáticas nos interesa poner de manifiesto la función Foco, pues por ella, notifican aquella información que supuestamente el entrevistador desconoce, por medio de la cual se puede ampliar la visión que tiene de la problemática que comentan.

Algunos de los sintagmas colocados como Foco en el Texto 1 son: $(1,2)$ : "...la juventud es muy apática", "...que el cincuenta por ciento de los parados en España sean jóvenes", (IV,2), "tener al joven mecanizao", (XIII,2), "...ahora mismo la droga". En el Texto 2 hallamos: (III,6), "Bueno y creo que se plantea bien oscuro", (IV,4), "...y ves a los demás por arriba", $(\mathrm{XI}, 4)$, "...se nos han dado las cosas muy fáciles". Los elementos destacados como función Foco son de corte distinto. L.2 ve un futuro preocupante pero no se limita a quejarse, sino que los problemas los presenta como Foco y los analiza; la visión de futuro se arraiga en el presente, desde el que hay que poner remedio y buscar soluciones conjuntas con el resto de la juventud. El L.3 se preocupa por el futuro, mas está muy cogido por el desencanto; en su visión prima el individuo sobre la colectividad y hace de un problema común a toda una generación, "su problema", siendo su actitud la de "sálvese quien pueda", tal y como expresa: (III,6), "...yo creo que se ve más bien... más bien mal, ise...se ve mal? que...que no...no hay trabajo y tal, pero sin embargo tú intentas decir que tú por lo menos vas a encontrarlo (mm)...". Sin embargo L.2 piensa que la concienciación colectiva puede producir el cambio de estructuras injustas.

Es importante destacar la actitud del entrevistador, que en todo momento es activa, sin cesar de colaborar, propicia un clima en el que los entrevistados se sienten cómodos, además hace alarde de buen conversador utilizando recursos persuasivos como la utilización de un léxico cercano al argot de sus interlocutores, siempre con un tono cordial, 
haciendo posible la comunicación.

Para finalizar destacaremos que ambos interlocutores colocan el paro entre las inquietudes primordiales y declaran como un valor fundamental de la juventud el impacto que ejerce la desilusión y la falta de alternativas, que aboca a muchos de ellos al pasotismo y a la desespèranza. En términos generales podemos destacar que L.2 mantiene una vinculación interactiva más fuerte, es más extrovertido y se relaciona con mayor confianza con el L.1, a la vez que muestra un conocimiento más directo y profundo de los temas. L.3 está más encerrado en sí mismo, se mantiene más distante de la problemática sobre la que opina y en su relación con el entrevistador, aportando pocas ideas y con una expresión menos ágil. La expresividad es mayor en las intervenciones del L.2, hecho que advertimos en la utilización de términos relevantes de ámbitos léxicos determinados, como el sociopolítico: "asociación política", "colectivo de jóvenes", "organización de base"; o expresiones coloquiales de baja extracción: "sacarle el pringue", "darse ellos el lote", junto con expresiones de sectores juveniles: "pequeños camellos", etc. Por el contrario el L.3 no se expresa con un lenguaje demasiado marcado, sino que podemos caracterizar su dicción como "coloquialmente aséptica".

\section{Conclusiones}

Pensamos que el estudio del leguaje oral redundará en el conocimiento del ser humano y en definitiva, este trabajo es un ejemplo más de la necesidad de acercamientos al hecho comunicativo desde una perspectiva interdisciplinar, que pretende destacar cuál es la aportación que la Lingüística puede hacerle a la sociología completando los hallazgos obtenidos a partir de las encuestas sociológicas, mediante la deducción de actitudes siempre partiendo del análisis del discurso. Y esto debido a que el hombre por su lenguaje construye el mundo y se constituye a sí mismo, dando su visión de lo que le rodea; las conclusiones obtenidas han sido posibles merced a que la subjetividad tiene marcas lingüísticas, datos con los que nosotros hemos trabajado para realizar este estudio interactivo, el cual pensamos, da cuenta del fenómeno que se produce cuando dos sujetos intercambian ideas. Siendo nuestro principal objetivo, adentrarnos un poco más, en el mundo de las relaciones humanas, con la pretensión de que sea la nuestra, una aportación, aunque limitada, aceptable.

\section{Referencias bibliográficas}

Allen, D. E. y Guy, R. F. (1978): Conversation Analysis. The Sociology of Talk, The HagueParís, Mouton.

Austin, J.I. (1971): Palabras y acciones, Buenos Aires, Paidós, $3^{3 a}$ edic.

Bally, Ch. (1977): Linguistica generale e Linguistica francese (fragmento), en Le teorie sintattiche del novecento, de S. Stati (comp.), Bolonia, II Mulino, pp. 23-35.

Benveniste, E. (1974): "Los niveles de análisis lingüístico", en Problemas de lingüística general, tomo I, Méjico, Siglo XXI, $4^{\text {a edic. }}$

Birdwhistell, R. L. (1979): El lenguaje de la expresión corporal, Barcelona, Colección comunicación visual.

Bühler, K. (1979), Teoría del lenguaje, Madrid, Alianza.

Cascales, $\mathrm{M}^{ \pm}$N. y Chillón, J.L. (1986): Juventud en la región de Murcia (1985), Editora Regional de Murcia.

Dik, S.c. (1981): "Funciones pragmáticas", en Gramática funcional, Madrid, Segel. 
Ducrot, O. (1980): Les Mots du discours, París, Minuit.

Ducrot, O. (1981): Decir y no decir, Barcelona, Anágora.

Duranti, A. (1986): "The audience as co-author: An Introduction", en Test 6-3, Berlín-New York-Amsterdam, Mouton-De Gruyter, pp. 239-247.

Fuchs, C. (1981): "Les problématiques énonciatives: Esquisse d'une présentation historique et critique", "Dans le champ pragmaticoenonciatif", en $D R L A V, \mathrm{n}^{\circ} 25$, París, pp. 3539.

Grice, H. P. (1975): "Logic and conversation", en Cole/Morgan (eds.), Syntax and Sociolinguistics, Laver/Hutchinson, 1972, pp. 374-405.

Grumbach, J. S. (1979): "Per una tipologia dei discorsi", en Lingua Discorso Società, Parma, Pratiche Editrice.

Gruning, B. N. (1981): "Plusiers pragmatiques", "Dans le champ pragmaticoenonciatif", en DRLAV, no 25, París, pp. 101-118.

Guespin, L. (1984): "Introduction", en Langages, no 74, París, Larousse, pp. 5-14.

Guespin, L.: "Interaction verbale et catégorisation dans l'entretien: sur une enquête sociologique à Louviers", op. cit., pp. 47-91.

Gurruchaga, $\mathrm{M}^{\mathrm{a}}$ L. (1981): "Análisis de una secuencia conflictiva en una discusión radiofónica", en Anales de la Universidad de Murcia, vol. XXXVIII, n² 2, pp. 209-223. Jiménez Cano, J. M" (1983): "Presupuestos teóricos para una grafémica textual", en Estudios de Lingüistica, no 1 , Universidad de Alicante, pp. 227-248.

Johnstone, B. (1986): "Arguments with Khomeini: Rhetorical situation and persuasive style in crosscultural perspective", en Text, vol. 6-2, Berlín-New York-Amsterdam, Mouton de Gruyter, pp. 170-187.

Lozano, J. et al. (1982): Análisis del discurso. Hacia una semiótica de la interacción textual, Madrid, Cátedra.

Latella, G. (1986): "Enfoque semiótico de la interacción", en LEA VIII, pp. 169-175.

Meunier, A. (1979): "Points de repère historiques pour l'étude de la notion de modalité", "Mélanges de systeme et sémantique", en $D R L A V, \mathrm{n}^{\circ} 21$, París.

Meunier, A.: "Grammaires du française et modalités. Matériaux pour l'histoire d'une nebuleuse", "Dans le champ pragmaticoenonciatif", en $D R L A V, \mathrm{n}^{\circ} 25$, París.

Psathas, G. (1969). "Analyzing Dyadic Interaction", The Analysis of Comunication Content, G,. Gerbener, O. R. Holsti, K. Krippendorff, W. J. Paisley, and P. J. Stone (eds.), New York: Wiley.

Reardon, L. K. (1983): La persusasión en la comunicación. Teoría y Texto, Barcelona, Paidós Comunicación.

Ramón Trives, E. (1980): "Nuestro hablar: proceso pragmáticamente no exento", en Monteagudo, $\mathrm{n}^{\mathrm{Q}}$ 68, Universidad de Murcia, pp. 13-20.

Recanati, F. (1979): La transparencia y la enunciación. Introducción a la pragmática, Argentina, Hachette.

Saussure, F. de (1980): Curso de Lingüistica General, Barcelona, Akal.

Searle, H. R. (1980): Actos de habla, Madrid, Cátedra.

Vera, A. (1979): "La estructura del campo deíctico-personal en español: el pronombre", Analecta Malacitana, II, 1, pp. 3-25.

Vigara Tauste, A. M (1980): Aspectos del español hablado, Madrid, Sociedad Española de Librería.

Wuderlich, D. (1972): "Pragmatique, situation d'énonciation et deixis", Langages, 26, pp. 34-58.

Zaefferer, D. (1984): "Hacia una semiótica universal de tipos oracionales", REL, 14, 2, pp. 421-434. 